\title{
WORLDRANGERS - A PEDAGOGICAL APPROACH TO A SUSTAINABLE DEVELOPMENT
}

\author{
Haase, Hans-Martin - Ekler, Stella - Hartmannsgruber, Martin \\ University of Education, Schwäbisch Gmünd, Germany, \\ Department of Natural Sciences, Biology
}

\begin{abstract}
Our consumer-oriented lifestyle necessarily leads to a steadily increasing utilisation of nature and its resources. A central element of environmental education focuses, therefore, on a promotion of sustainable lifestyles within our existing economic growth structures. The educational programme Worldrangers includes three intentions: (i) attaching an ethic to sustainability thinking, (ii) trying to counter the increasing trend towards the destruction of nature and consumption of natural resources as well as (iii) challenging our consumeroriented lifestyles. Specific consideration is given to potential synergistic effects between an original encounter and cognitive knowledge transfer. The one week programme was introduced and completed in an ecologically oriented residential field centre. A substantial ceiling (respectively bottom) effect concerning the attitudes of the participating pupils was observed for the pre-test scores. Therefore, the shifts in attitude scores were low but occurred into the desired direction. The lesson elements which focused on hands-on activities and real life situations lead to significantly increased knowledge. An additional study, that was conducted five years after the intervention, indicated a very positive long-term effect of the programme Worldrangers.
\end{abstract}

\section{Introduction}

The scientific community is having a controversial discussion relating the effects of short-term outdoor ecology education on long-term variables of environmental perception. This fact is not surprising, because up to now there is no common agreement in constructing such ecological education programmes. Thus, the aim of this investigation was to develop an educational programme in accordance with the existing theoretical background and current practical experiences (cf. Haase \& Bogner, 2002; Haase, 2004).

The subject components of this education programme are derived from the main problems of the ecological crises. Nearly all ecological problems are the consequence of our industrial lifestyle, which we all consider as being quite normal. But it is Mr. Average who is the perpetrator of the worldwide ecological disaster. The $\mathrm{CO}_{2}$ emission can be used as an indication parameter for consuming fossil fuel. An ordinary German family produces on average approximately 30 tons of $\mathrm{CO}_{2}$ each year. Even more than mobility, heating or the use of electricity, 
consumer goods have an enormous contribution to the total $\mathrm{CO}_{2}$ emission. Thus, the Worldrangers programme scrutinizes the consumer society.

Perhaps, the ethical model of a sustainable development is the most important pillar for designing modern environmental education programmes. If one uses the perspective from space of the earth at night, it is obvious, that there is no sustainable development at the moment.

Besides, there is an imbalance in using resources represented by the lights of the industrialized regions and the darkness in the developing countries. Red coloured areas are oilfields where natural gas is burned off. Pink areas point to burning tropical rain forest. This image is not used as a means to frighten the children. Nevertheless, it emphasises the seriousness of the situation. In the same context they are to realize the responsibility of the industrialized nations in which they grow up.

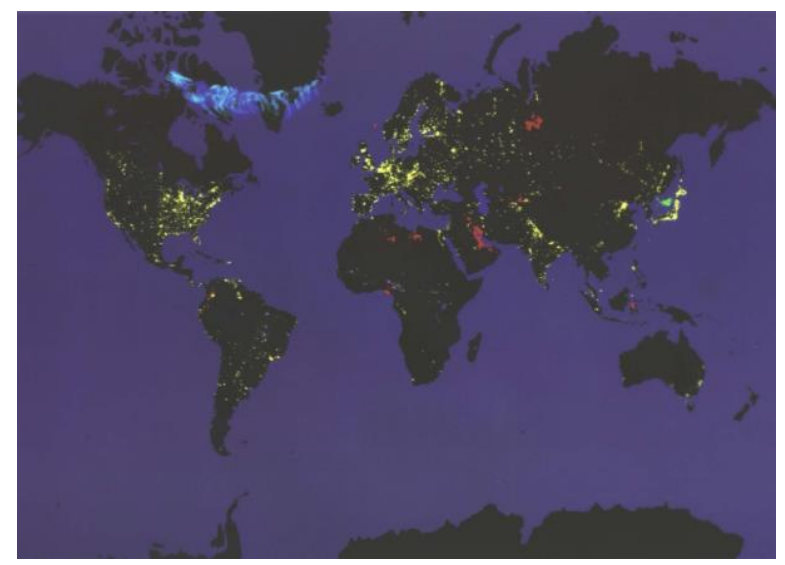

Figure 1

Use of resources (Source: Die Zeit, Magazin [Hg.], Licht Spezial, Nr. 12, 02.04.1998)

\section{Conception of the Worldrangers programme}

The Worldrangers programme was designed for elementary school children who stay in an ecological residential field centre for the duration of one week. All of the lessons are introduced with a typical everyday life situation of children. One of the lessons shows the ecological impacts of daily used fruits which are

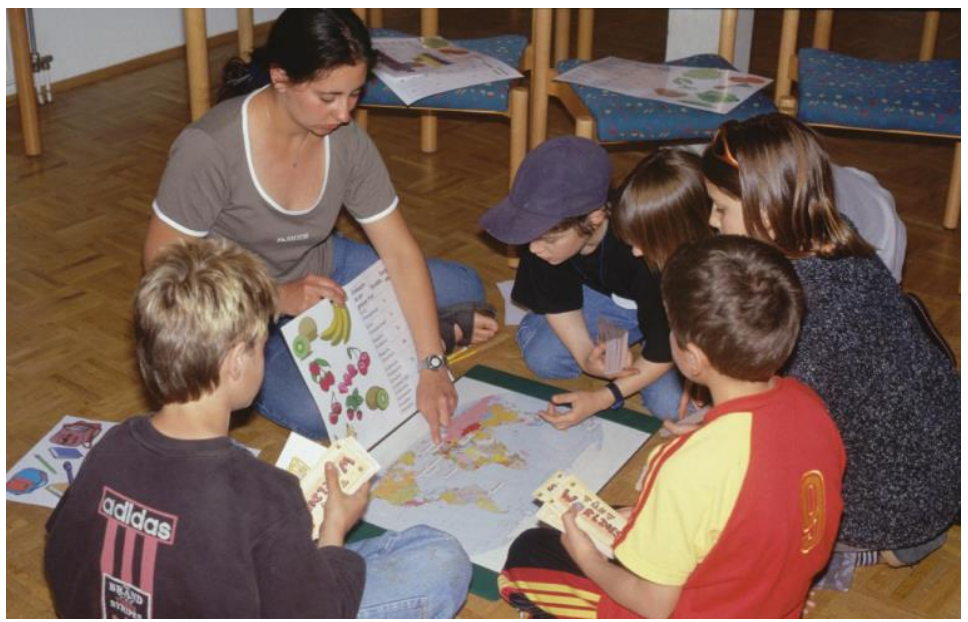
produced far away. In a playful way, the pupils can follow the way and distance, which the products travel before they arrive at their homes. 
As a contrast, they comprehend that regional and especially seasonal agricultural products have a favourable effect on getting closer to a sustainable development. With the help of this exemplary concept, children get the really good feeling and the knowledge that they themselves can have an impact on preserving the ecological system. Being able to actively influence a situation is the key for motivating pupils (cf. Palmberg, I.E. \& Kuru, J., 2000; Baur \& Haase, 2013).

\section{Research question and hypothesis}

The study investigates whether a short-term environmental programme has effects on long-term variables of environmental perception. The hypothesis $\left(\mathrm{H}_{1}\right)$ states that it does have an influence. The rival hypothesis $\left(\mathrm{H}_{0}\right)$ would contradict that assessment.

\section{Method}

\section{Research design}

Altogether, 13 German school classes $(\mathrm{N}=322)$ took part in the study. The pupils were between 10 and 12 years of age. Female and male pupils were equally balanced. Nine additional classes served as a control parameter. They also stayed at the ecological field centre for one week but did not take part in the Worldrangers programme. Still, they also went through environmental programmes designed by other teachers.

All pupils were tested on content knowledge and environmental attitudes on the first day of the programme. Four weeks later, the children were tested again. The break of three weeks was chosen to exclude short-term effects related to the special situation at the field centre (cf. Bogner, 1998). For each class, the programme was carried out by the same Worldrangers team to rule out the teacher variable, which is one of the most important factors in education (cf. Hattie, 2009).

\subsection{Measuring instruments}

The knowledge test was evaluated with a t-test. As the results of the test for environmental perception were not normally distributed, the Wilcoxon-test was used for these parameters.

\subsubsection{Knowledge test}

Environmental knowledge was tested through a questionnaire of 16 items with a five point Likert-scale. As all of the questions were connected to the content of the Worldrangers programme, the questionnaire was developed and tested by the author. For answering the question no specific knowledge or technical terms were necessary, so the pupils could also understand them in the pre-test. This fact also ensured comprehension for the children of the control group. 


\subsubsection{Environmental attitude test}

For measuring environmental attitudes, a well tested instrument, developed by Bogner \& Wiseman (cf. 1999) was used. It consists of the two scales utilization and preservation. Each of the two scales consists of four subscales that are represented by four items each.

\section{Results}

\subsection{Knowledge}

In 8 of the 16 questions the Worldrangers group improved significantly while the control group did not show any significant change. For question 4 both groups answered worse than before the intervention which is probably due to a misunderstanding. In the remaining 7 questions neither of the groups showed significant changes.

\subsection{Environmental attitude}

Although the environmental attitude changes of the test group were minor, they occurred in the desired direction. This could be due to a ceiling effect in the pretest in which not only the test group, but also the control group scored extremely high compared to other ordinary classes.

\subsection{New qualitative long term study}

Additionally to the quantitative results, a new qualitative study focused on long term effects of the short term programme Worldrangers (cf. Ekler, 2013). To investigate this, nine pupils who had been to the field centre Licherode were interviewed five years after the intervention. Five of them had taken part in the Worldrangers programme, the other four had not. In comparison with this control group, Worldrangers (i) had a more realistic perception of the ecological crisis, (ii) developed a clear responsibility towards the environment, (iii) showed a higher willingness for an ecological lifestyle and (iv) told about concrete ecofriendly actions which had a clear reference to the Worldrangers programme.

\section{Conclusion}

This study clearly shows the positive effects of the Worldrangers programme compared to the control group that also stayed at the same field centre and received environmental teaching as well. There are two plausible explanations for the ceiling effect mentioned above. First, it is well known in the scientific community, that children between 10 to 12 years of age have a high affection to nature. Second, it is likely that the teachers who took their classes to Licherode have chosen this specific field centre for its ecological orientation. Hence follows the assumption that for those teachers ecology is an important topic. Naturally, they have incorporated this in their teachings already in the months or years before the field trip. This might explain, why the pupils scored so high before the 
intervention. Another reason could be the excitement, that the pupils had at the beginning of the field trip. As the post-test was filled in four weeks later at school, the "normal" school atmosphere probably was responsible for the drop in scores especially in the control group.

\section{Future prospects}

Encouraged by Ekler's promising results as well as a study by Drissner et. al. (2010) we are focusing our future research on the long-term effects of the Worldrangers programme. Drissner et al. could show that even half-day interventions (in this case the topic was invertebrates) can positively influence pupils' attitudes towards the environment.

In a first step, Ekler's results should be cross validated using a larger sample.

\section{Bibliography}

Baur, Armin, Haase, Hans-Martin (2013): The influence of active participation and organization in environmental protection activities on the environmental behaviour of pupils: Study of a teaching technique. In: Environmental Education Research. [Published online: 17 Oct 2013]

Bogner, Franz X. (1998): The influence of short-term outdoor ecology education on long-term variables of environmental perception. In: The Journal of Environmental Education, 29, p. 17-29.

Bogner, Franz X., Wiseman, Michael (1999): Towards measuring Adolescent Environmental Perception. In: European Psychologist, 4. p. 139-151.

Drissner, Jürgen, Haase, Hans-Martin, Hille, Katrin (2010): Short-term Environmental Education - Does it work? - An evaluation of the 'Green Classroom'. In: Journal of Biological Education, 44, 4, p. 149-155.

Ekler, Stella (2013): Langfristige Wirkungen des Bildungsprogramms Worldrangers in Bezug auf das Umweltbewusstsein und Umwelthandeln, Diploma Thesis, Pädagogische Hochschule Schwäbisch Gmünd.

Haase, Hans-Martin; Bogner, Franz X. (2002): Nachhaltigkeit und Umweltbildung: Möglichkeiten pädagogischen Wirkens. In: Natur und Kultur, 3, p. 75-94.

Haase, Hans-Martin (2004): Worldrangers: Ein pädagogischer Beitrag für eine nachhaltige Entwicklung: Hintergründe und Praxisvorschläge für eine zeitgemäße Umweltbildung, Dr. Kovač: Hamburg.

Hattie, John (2009): Visible Learning. A Synthesis of over 800 meta-analyses relating to achievement. London \& New York: Routledge, Taylor \& Francis Group, p. 22. 
Haase, Hans-Martin - Ekler, Stella - Hartmannsgruber, Martin

Palmberg, Irmeli E., Kuru, Jari (2000): Outdoor activities as a basis for environmental responsibility. In: The Journal of Environmental Education, 31, p. 32-36. 